\title{
Suburethral sling at the time of radical prostatectomy in patients at high risk of postoperative incontinence
}

\author{
O. LENAINE WESTNEY, SHELLIE SCOTT, CHRISTOPHER WOOD, TERESA EDDINGS, MARCELLA M. JOHNSON*, \\ JENNIFER M. TAYLOR, EDWARD McGUIRE+ and LOUIS L. PISTERS \\ Departments of Urology and *Bostatistics \&t Applied Mathematics, The University of Texas M. D. Anderson Cancer Center, Houston, Texas; and the \\ fDepartment of Urology, University of Michigan, Ann Arbor, Michigan, USA.
}

Accepted for publication 7 March 2006

\section{OBJECTIVE}

To evaluate the insertion of a urethral sling at the time of radical prostatectomy (RP) in men at high risk of urinary incontinence after RP.

\section{PATIENTS AND METHODS}

Between 1998 and 2000, 49 of 871 men undergoing RP at The University of Texas M.D. Anderson Cancer Center, were identified as at risk of urinary incontinence after $\mathrm{RP}$, based on their age ( $>65$ years), previous transurethral resection of the prostate, previous radiation therapy, clinical stage, and obesity (body mass index of $\geq 30 \mathrm{~kg} / \mathrm{m}^{2}$ ). These 49 men had a suburethral sling inserted at the time of RP, and incontinence after surgery was evaluated using pad counts and patient-completed questionnaires. Retrospectively, incontinence rates and complications in these men were compared with 122 men also at high risk of urinary incontinence after RP who did not have a sling inserted at the time of RP (control group).

\section{RESULTS}

In all, 29 of 49 men (59\%) with a suburethral sling reported using either no pad or one pad per day for urinary leakage at 6 months after $\mathrm{RP}$, compared with 83 of 118 (70\%) in the control group. At 12 months after RP, 34 of 46 (74\%) men with a suburethral sling reported using no or one pad, compared with 75 of 89 $(84 \%)$ in the control group. Seventeen (35\%) men were treated for urethral stricture in the sling group and $17(14 \%)$ in the control group $(P=0.001)$.

\section{CONCLUSION}

The urethral sling modification concurrent with RP is feasible, but does not decrease incontinence compared with a similar group of high-risk patients who did not have the sling modification. In addition, the stricture rate in the sling group was unacceptably high. Currently, we do not recommend the use of a urethral sling at the time of RP.

\section{KEYWORDS}

Urethral sling, post-prostatectomy incontinence

\section{INTRODUCTION}

Urinary incontinence (UI) after radical prostatectomy (RP) has become less of a problem in well-selected patients, but continues to be a major problem in a small subset of at-risk patients. Factors that increase the risk of UI after RP include: greater age, previous TURP, previous radiation therapy, clinical stage, and obesity [1-4], with overall UI rates of 3-51\% [5-7]. This reported variability in the rate of UI might depend on the methods of data collection and patient selection. Also, patients tend to report more incidences of $\mathrm{UI}$ than do physicians [8]. In men who have previously had radiation therapy, the use of urinary pads after RP is reported to be as high as 51\% $[8,9]$.

Although the exact cause of UI after RP is unknown, most patients have a component of stress UI secondary to intrinsic sphincter deficiency $[10,11]$. In women with stressinduced UI the pubovaginal sling has successfully restored continence at rates of up to $82-92 \%$ at 48 months of follow-up [12-14]. The success rate of the bulbourethral sling used in men after RP has been more modest, i.e. $75 \%$ at 16 months of follow-up, including revisions [15]. The less invasive perineal bone anchor technique appears to have similar early success rates of $76-86 \%$ at 12 months $[16,17]$. Jorion $[18]$ reported the use of a rectus fascial sling to suspend the vesico-urethral anastomosis in a group of men at low risk of treatment-induced UI after $\mathrm{RP}$. The resulting continence rate was 100\% at 12 months, which was similar to the rate of 93\% in the comparison group. However, the sling group appeared to achieve continence more rapidly than the comparison group.

We conducted a non-randomized clinical trial to compare the efficacy and safety of immediate suburethral sling insertion at the time of RP, with no sling used in a control group, in men at high risk of UI after RP.

\section{PATIENTS AND METHODS}

Between October 1998 and March 2000, 871 men had RP at the University of Texas M.D. Anderson Cancer Center. Of these, 49 men considered to be at high risk of UI after RP had a urethral fascial sling inserted at the time of RP. The protocol was approved by the Institutional Review Board (IRB), and all patients gave informed consent for treatment. The sling group was compared with a separate group of men who were also felt to be at high risk of UI after RP, comprising 122 men with locally advanced prostate cancer who received neoadjuvant systemic therapy on protocol followed by RP alone. Factors considered to increase the risk of UI were previous radiation therapy, age $>65$ years, advanced stage disease $(\geq T 3)$, obesity (body mass index $\geq 30 \mathrm{~kg} / \mathrm{m}^{2}$ ), and previous TURP (Table 1) [19]. All men in the sling group had at least one risk factor: 14 of the 49 men had one risk factor, 15 had two, and 21 had three or more. Many men in both 
TABLE 1 Preoperative risk factors for urinary incontinence and disease characteristics

\begin{tabular}{|c|c|c|c|}
\hline Factor & Sling group, n (\%) & Control group, n (\%) & $\mathrm{P}$ \\
\hline $\bar{N}$ & 49 & 122 & \\
\hline \multicolumn{4}{|l|}{ Risk factor, n (\%) } \\
\hline Previous radiotherapy & $6(12.2)$ & $3(2.5)$ & $0.017^{*}$ \\
\hline Age $>65$ years & $21(42.9)$ & $42(34.4)$ & $0.381^{*}$ \\
\hline Clinical stage $\geq T 3$ & $10(20.4)$ & $31(25.4)$ & $0.556^{*}$ \\
\hline Obesity (BMI $\geq 30 \mathrm{~kg} / \mathrm{m}^{2}$ ) & $28(57.1)$ & 48 (39.3) & $0.042^{*}$ \\
\hline Previous TURP & $5(10.2)$ & $2(1.6)$ & $0.021^{*}$ \\
\hline Previous prostate gene therapyt & $14(28.6)$ & 0 & $<0.001^{*}$ \\
\hline Previous systemic therapy $\neq$ & $12(24.5)$ & $92(75.4)$ & $<0.001^{*}$ \\
\hline \multicolumn{4}{|l|}{ Disease characteristics, n (\%) } \\
\hline \multicolumn{4}{|l|}{ Pre-salvage PSA level $(\mathrm{ng} / \mathrm{mL})$ : } \\
\hline $0-4.0$ & $8(16.3)$ & $12(9.8)$ & \multirow[t]{4}{*}{$0.014^{\mathrm{a}}$} \\
\hline $4.1-10.0$ & $28(57.1)$ & $44(36.1)$ & \\
\hline $10.1-20.0$ & $7(14.3)$ & $35(28.7)$ & \\
\hline$>20.0$ & $6(12.2$ & $31(25.4)$ & \\
\hline \multicolumn{4}{|l|}{ Biopsy Gleason score: } \\
\hline 6 & $9(18.8)$ & $16(13.1)$ & \multirow[t]{6}{*}{$0.004^{a}$} \\
\hline 7 & $25(52.1)$ & $33(27.1)$ & \\
\hline 8 & $10(20.8)$ & $35(28.7)$ & \\
\hline 9 & $3(6.3)$ & $32(26.2)$ & \\
\hline 10 & $1(2.1)$ & $6(4.9)$ & \\
\hline Hormone effect§ & 1 & 0 & \\
\hline \multicolumn{4}{|l|}{ Clinical stage: } \\
\hline T1b-c & $13(26.5)$ & $7(5.7)$ & \multirow[t]{4}{*}{$0.002^{\mathrm{a}}$} \\
\hline $\mathrm{T} 2 \mathrm{a}$ & $8(16.3)$ & $33(27.1)$ & \\
\hline $\mathrm{T} 2 \mathrm{~b}$ & $18(36.7)$ & $51(41.8)$ & \\
\hline T3a-b & $10(20.4)$ & $31(25.4)$ & \\
\hline \multicolumn{4}{|c|}{$\begin{array}{l}\text { *Fisher's exact test. Preoperative prostate injection with p53 gene/adenovirus vector [19]. \#A } \\
\text { combination of systemic therapies was administered: chemotherapy, hormone ablation, TNP-470 } \\
\text { angiogenesis inhibitor. §One patient was excluded from the statistical comparison due to hormone effect } \\
\text { (i.e. no Gleason score). } \llbracket A l l 13 \text { men in the sling group had clinical stage T1c. }{ }^{\circ} \text { Chi-square test. }\end{array}$} \\
\hline
\end{tabular}

FIG. 1. Location of the Penrose drain underneath the anastomosis.

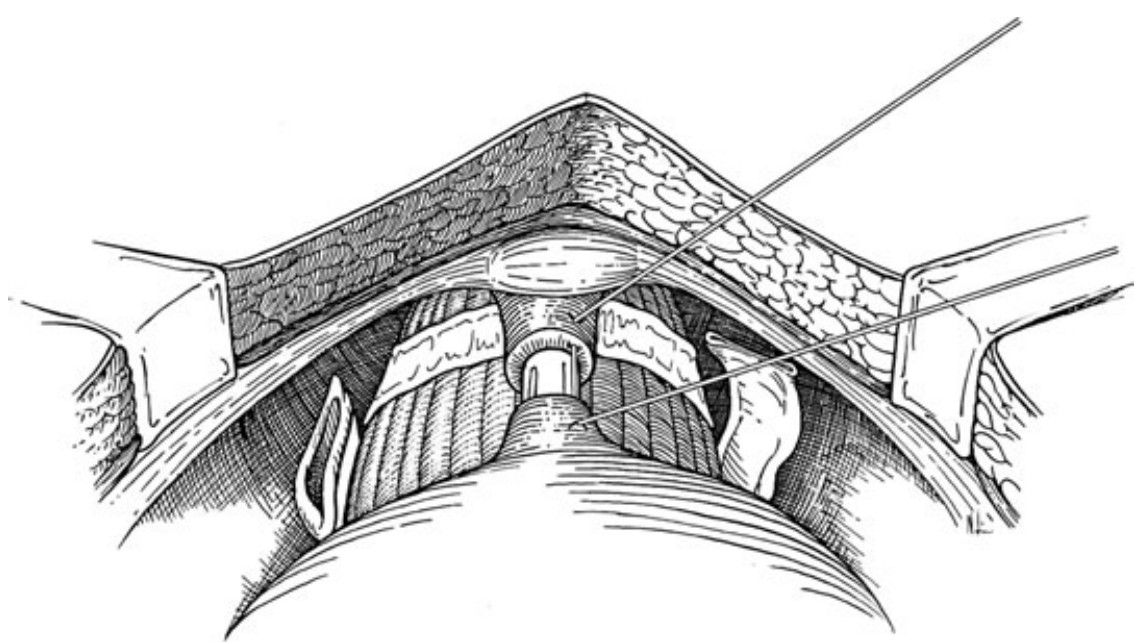

groups had locally advanced disease and received neoadjuvant therapy before $\mathrm{RP}$ on various IRB-approved protocols. In one of these protocols, men with locally advanced prostate cancer were treated with neoadjuvant gene therapy before RP. These men received $20-80$ separate transperineal injections of aqueous liquid into the prostate. We noted extensive apical scarring in these men that could have damaged the urinary sphincter, resulting in a greater risk of UI. Other men received a variety of systemic therapies before RP, including hormonal therapy, systemic chemotherapy, and antiangiogenic therapy, all on protocols approved by the IRB. A group of these men who were also at high risk of UI because of the advanced clinical stage of their disease were compared to the sling treatment group. Table 1 lists the pathological disease characteristics for men in the sling treatment and control groups; these results indicate the prevalence of locally advanced disease in our study population. The median (range) age of the men in the sling group at the time of RP was 63.6 (44-77) years and of the control group was 62 (41-73) years.

Before surgery, all men in the sling group had urodynamic testing, which included an estimate of postvoid residual volume, uroflowmetry, and a cystometrogram. The Valsalva leak-point pressure and compliance were determined in accordance with ICS standards [20]. One man in the sling group was incontinent before RP and used 1-2 pads per day. All the other men in the sling group were continent subjectively and objectively before RP.

A retropubic RP was performed in a standard fashion. After removing the prostate specimen and placing the vesico-urethral anastomotic sutures, a $1.3-\mathrm{cm}$ Penrose drain was placed beneath the urethral stump as distally as possible (Fig. 1). We completed the anastomosis in the usual fashion over a Foley catheter. A fascial strip $\approx 1.5 \times 10 \mathrm{~cm}$ was then harvested vertically from rectus fascia along the midline incision (Fig. 2). After placing 0 polypropylene sutures on either end of the fascial strip, one of the sutures was attached to the end of the Penrose drain. Then, with gentle traction on the Penrose drain, the rectus fascial strip was guided underneath the anastomosis (Fig. 3). The sling was crossed over the anastomosis, compressing the lower half of the urethra. The sutures were brought through the fascia 
2-3 cm lateral to midline at the inferior end of the incision. The fascia was closed routinely and the sutures were tied loosely over the fascia accommodating one finger underneath the knot (Fig. 4). The Foley catheter was removed $\approx 3$ weeks after $\mathrm{RP}$.

The follow-up evaluation in the sling group included patient-reported pad counts and patient-completed UI assessment questionnaires (Appendix 1) at 3,6 and 12 months after RP. In the control group follow-up evaluation was by retrospective chart review for pad counts and physicianreported continence rates.

The UI rates and complications in the sling and the control groups were compared using the chi-square test or Fisher's exact test, with $P<0.05$ was considered to indicate statistical significance.

\section{RESULTS}

Although men in both the sling and the control groups were at greater risk of UI, the distribution of some risk factors was significantly different between the groups (Table 1). More men in the control group with clinical stage T3 disease had undergone previous systemic therapy $(P<0.56)$. There was a higher percentage of men in the sling group who had had previous radiation therapy $(P=0.017)$, were aged $>65$ years $(P=0.38)$, were obese $(P=0.04)$, had had previous TURP $(P=0.02)$ and previous gene therapy $(P<0.001)$. Table 1 lists the disease characteristics of men in the two groups. Table 2 shows the pad use after RP as determined from the patient-completed questionnaire in the sling group and by retrospective chart review for the control group. At 6 months, 59\% of men in the sling group reported using either no pad or one pad per day, vs $70 \%$ of men in the control group $(P=0.21)$. At 12 months, 74\% of men in the sling group reported using either no pad or one pad per day vs $84 \%$ in the control group $(P=0.17)$. Table 3 shows the complication rates; stricture was the most common complication, occurring in $17(35 \%)$ men in the sling group and $17(14 \%)$ in the control group $(P=0.001)$. The men in the sling group who developed strictures had the following risk factors for UI: previous radiation (two), age $>65$ years (11), previous gene therapy (seven), obesity
FIG. 2. The rectus facial sling.
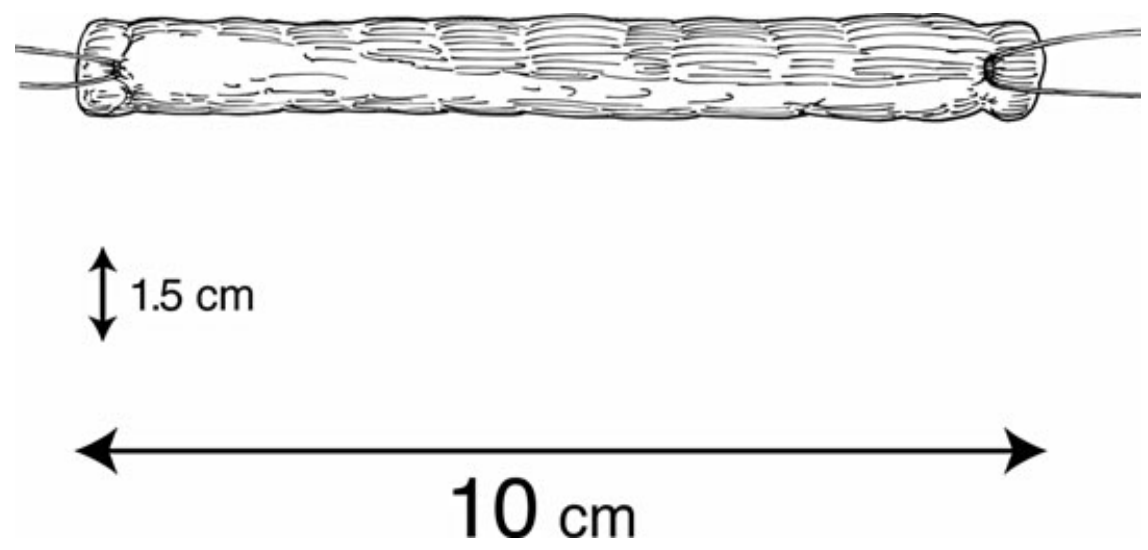

FIG. 3. Guiding the sling into position.

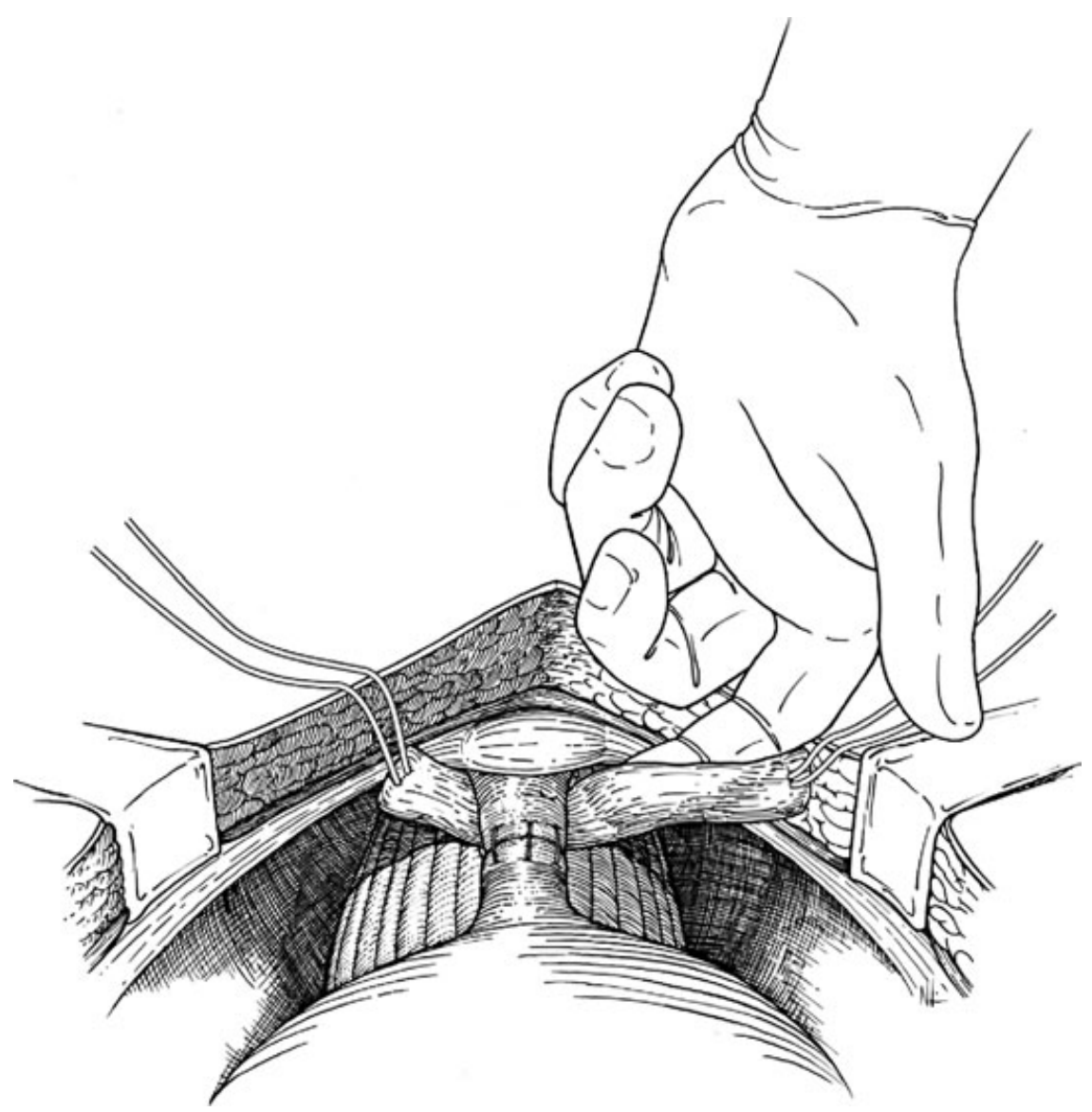

with a body mass index (BMI) of $>30 \mathrm{~kg} / \mathrm{m}^{2}$ (nine), and previous systemic therapy (four). Six of 17 patients with stricture had one risk factor and 11 had more than one. Based on Fisher's exact test, none of the factors were associated with stricture. Of these 17 men, four required visual internal urethrotomy (VIU), 11 were managed with dilatation alone, and the other two received both VIU and urethral dilatation. All complications, for both groups, were managed in the outpatient setting. 
FIG. 4. Sling suture tied loosely over index finger.

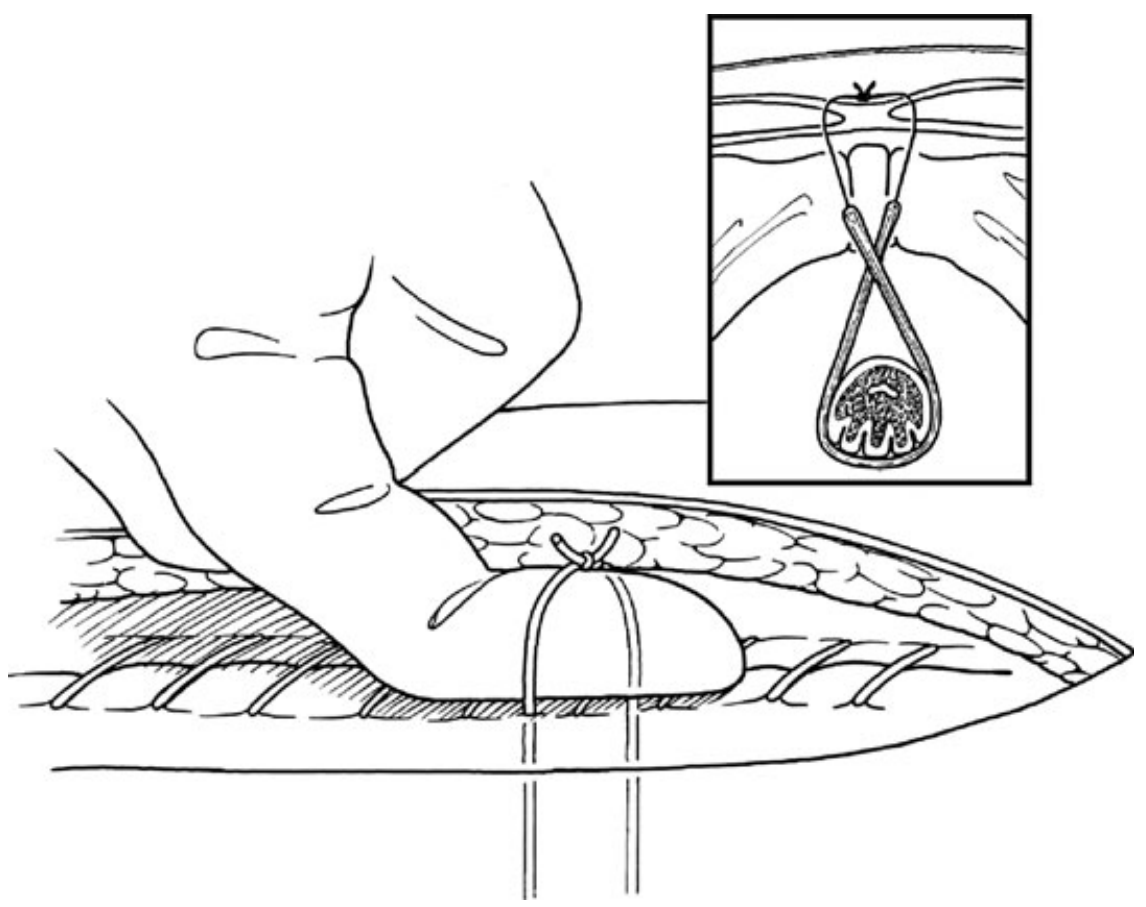

TABLE 2 Pad usage for men considered at high risk for urinary incontinence after RP

\begin{tabular}{|c|c|c|c|c|c|c|}
\hline & \multicolumn{2}{|c|}{ At 6 months, $\mathrm{n}(\%)$} & \multirow[b]{2}{*}{$P$} & \multicolumn{2}{|c|}{ At 12 months, n (\%) } & \multirow[b]{2}{*}{$\mathrm{P}$} \\
\hline & $\overline{\text { Sling group }}$ & Control group & & Sling group & Control group & \\
\hline $\bar{N}$ & 49 & 118 & & 46 & 89 & \\
\hline
\end{tabular}

No. of pads

used in $24 \mathrm{~h}$ :

\begin{tabular}{rrrrrrr}
0 & $19(38.8)$ & $52(44.1)$ & $0.258^{*}$ & $27(58.7)$ & $57(64.0)$ & $0.473^{*}$ \\
1 & $10(20.4)$ & $31(26.3)$ & & $7(15.2)$ & $18(20.2)$ & \\
2 & $6(12.2)$ & $17(14.4)$ & & $4(8.7)$ & $6(6.7)$ & \\
$\geq 3$ & $14(28.6)$ & $18(15.3)$ & & $8(17.4)$ & $8(9.0)$ & \\
\multicolumn{2}{l}{ Combining groups): } & & & & & \\
$0-1$ & $29(59.2)$ & $83(70.3)$ & $0.206+$ & $34(73.9)$ & $75(84.3)$ & $0.171+$ \\
$\geq 2$ & $20(40.8)$ & $35(29.7)$ & & $12(26.1)$ & $14(15.7)$ &
\end{tabular}

${ }^{*}$ Chi-square test; + Fisher's exact test.

\begin{tabular}{|c|c|c|c|}
\hline Complication & Sling group, $n(\%)$ & Control group, $n(\%)$ & TABLE 3 \\
\hline $\bar{N}$ & 49 & 122 & Complications after surgery \\
\hline Stricture ${ }^{*}$ & $17(34.7)$ & $17(13.9)$ & \\
\hline Hypercontinencet & $2(4.1)$ & $2(1.6)$ & \\
\hline Incisional hernia & $1(2.0)$ & 0 & \\
\hline Pelvic abscess & $2(4.1)$ & $2(1.6)$ & \\
\hline Urine leak & $1(2.0)$ & $4(3.3)$ & \\
\hline Wound infection & $1(2.0)$ & $2(1.6)$ & ${ }^{*} \mathrm{P}=0.001$, Fisher's exact \\
\hline Seroma & $3(6.1)$ & $2(1.6)$ & test; thypercontinence \\
\hline Lymphocele & $3(6.1)$ & $4(3.3)$ & requiring intermittent \\
\hline Other & $19(38.8)$ & 89 (72.3) & catheterization. \\
\hline
\end{tabular}

\section{DISCUSSION}

Ul after RP can adversely affect the patients' quality of life. Whereas UI is an uncommon situation in low-risk patients, some patients with high-risk features may become incontinent after RP. Previous studies suggested that age, previous TURP, previous external beam radiation therapy, and obesity are risk factors for UI after RP [1-4]. The present phase I-II study was designed based on the premise that, if a surgical modification could be made at the time of RP on preselected high-risk patients, UI after RP could be reduced, decreasing the psychosocial and economic burden of treatment.

The effectiveness and durability of the pubovaginal sling was shown in women with stress UI, and had low morbidity [12-14]. As all, or at least a component, of UI after RP is stress-related we hypothesized that a urethral sling might appropriately treat this condition, as it treats stress UI in females. We acknowledge the differences in the patient groups, especially the high-risk group of men in the present study compared with the typical woman who has a sling procedure. These men had a combination of risk factors, including significant preoperative trauma to the prostate with potential injury to the continence mechanism from cancer therapy. Another difference between the present study and published experience in women with the pubovaginal sling is the presence of a fresh vesico-urethral anastomosis, which might have contributed to our stricture rate.

Continence rates were no better in the sling group than in the control group, with 59\% (29/49) of the sling group and $70 \%(83 / 118)$ of controls reporting the use of $0-1$ pads per day. At 12 months, UI in the sling group improved to 74\% reporting the use of 0-1 pads, but this was no different from the control group, which had $84 \%$ of men reporting the use of 0-1 pad.

All complications were managed in the outpatient setting. Urethral strictures were the primary complication, occurring in 35\% (17/49) of the men in the sling group. The stricture rate was significantly higher in the sling than in the control group $(P=0.001)$. We think that the sling might have increased the inflammation around the anastomosis, resulting in a higher stricture rate. Strictures could also result from trauma to the anastomosis from manipulation of the 
Penrose drain and placing the sling. Because different surgeons performed the sling procedure, technical variations in the placement and tension of the sling might have contributed to strictures in some cases. Of the three men who were hypercontinent, two had strictures and one had detrusor instability. Other complications appear to be unrelated to placing the urethral sling (Table 3).

The present study has significant limitations. A primary weakness is the lack of randomization. We compared the sling group to men who received neoadjuvant systemic therapy on protocol before RP. There were significant differences in the distribution of risk factors for UI between the sling and the control groups, which might have biased our results against the sling group. Furthermore, UI was assessed by patient-reported pad counts in the sling group and retrospective chart-assessed pad counts in the control group. This might represent further bias against the sling group. Although we cannot exclude a small potential benefit for the sling in a subset of high-risk patients, we do not think that the sling modification is beneficial enough to warrant evaluation in a phase III study.

In conclusion, the present study was a nonrandomized trial comparing 49 men at high risk of UI after RP who had a urethral sling inserted at the time of RP, with 122 men (control group) who did not have a sling inserted. We conclude that immediate sling insertion does not improve continence, and results in a higher incidence of stricture. We do not recommend suburethral sling insertion at the time of RP to avoid UI.

\section{ACKNOWLEDGEMENTS}

Supported by the Cancer Center Core Grant CA16672 from the National Cancer Institute and a grant from the American Foundation of Urologic Disease.

\section{CONFLICT OF INTEREST}

None declared.

\section{REFERENCES}

1 Eastham JA, Kattan MW, Rogers E et al. Risk factors for urinary incontinence after radical prostatectomy. J Urol 1996; 156: 1707-13
2 Kerr LA, Zincke H. Radical retropubic prostatectomy for prostate cancer in the elderly and the young: complications and prognosis. Eur Urol 1994; 25: 305-12

3 Elder JS, Gibbons RP, Correa RJ Jr, Brannen GE. Morbidity of radical perineal prostatectomy following transurethral resection of the prostate. J Urol 1984; 132: $55-7$

4 Rogers E, Ohori M, Kassabian VS, Wheeler TM, Scardino PT. Salvage radical prostatectomy: outcome measured by serum prostate specific antigen levels. J Urol 1995; 153: 104-10

5 Fowler FJ Jr, Barry MJ, Lu-Yao G, Roman A, Wasson J, Wennberg JE. Patient-reported complications and follow-up treatment after radical prostatectomy. The National Medicare Experience: 1998-90. Urology 1993; 42: 622-9

6 Hautmann RE, Sauter TW, Wendoroth UK. Radical retropubic prostatectomy: morbidity and urinary continence in 418 consecutive cases. Urology 1994; 43 (Suppl. 2): 47-51

7 Lerner SE, Blute ML, Zincke H. Critical evaluation of salvage surgery for radiorecurrent/resistant prostate cancer. J Urol 1995; 154: 1103-9

8 Talcott JA, Rieker P, Propert KJ et al. Patient-reported impotence and incontinence after nerve-sparing radical prostatectomy. J Nat/ Cancer Inst 1997; 89: 1117-23

9 Amling $\mathrm{CL}$, Lerner SE, Martin SK, Slezak JM, Blute ML, Zincke H. Deoxyribonucleic acid ploidy and serum prostate specific antigen predict outcome following salvage prostatectomy for radiation refractory prostate cancer. J Urol 1999; 161: 857-63

10 Wein A. In discussion of: Steiner MS, Morton RA, Walsh PC, Impact of anatomical radical prostatectomy on urinary continence. J Uro/ 1991; 145: 512-4

11 Groutz A, Blaivas JG, Chaikin DC, Weiss JP, Vanhaaren M. The pathophysiology of post-radical prostatectomy incontinence: a clinical and video urodynamic study. J Urol 2000; 163: 1767-70

12 Blaivas JG, Jacobs BZ. Pubovaginal fascial sling for the treatment of complicated stress urinary incontinence. J Urol 1991; 145: 1214-8

13 McGuire EJ, Bennett CJ, Konnak JA, Sonda LP, Savastano JA. Experience with pubovaginal slings for urinary incontinence at the University of Michigan. J Urol 1987; 138: 525-6

14 Morgan JE, Farrow GA, Stewart FE. The Marlex sling operation for the treatment of recurrent stress urinary incontinence: a 16-year review. Am J Obstet Gynecol 1985; 151: 224-6

15 Schaeffer AJ, Clemens JQ, Ferrari M, Stamey TA. The male bulbourethral sling procedure for post-radical prostatectomy incontinence. J Urol 1998; 159: 1510-5

16 Madjar S, Jacoby K, Giberti C et al. Bone anchored sling for the treatment of postprostatectomy incontinence. J Urol 2001; 165: 72-6

17 Comiter CV. The male sling for stress urinary incontinence: a prospective study. J Urol 2002; 167: 597-601

18 Jorion JL. Rectus fascial sling suspension of the vesicourethral anastomosis after radical prostatectomy. J Urol 1997; 157: 926-8

19 Pisters LL, Pettaway CA, Troncoso P et al. Evidence that transfer of functional p53 protein results in increased apoptosis in prostate cancer. Clin Cancer Res 2004; 10: 2587-93

20 Abrams P, Cardozo L, Fall M et al. The standardization of terminology of lower urinary tract function: report from the Standardization Sub-committee of the International Continence Society. Neurourol Urodyn 2002; 21: 167-78

Correspondence: Louis L. Pisters, Department of Urology, Unit 1373, The University of Texas M. D. Anderson Cancer Center, 1515 Holcombe Boulevard, Houston, TX 77030, USA.

e-mail: Ipisters@mdanderson.org

Abbreviations: RP, radical prostatectomy; UI, urinary incontinence; IRB, Institutional Review Board; VIU, visual internal urethrotomy; BMI, body mass index.

\section{APPENDIX 1}

SLING PROTOCOL FOLLOW-UP QUESTIONNAIRE

Medical Record Number:

Last Name:

First Name:

Months Since Surgery:

Today Date: 
Number of pads used for urine leakage in last $24 \mathrm{~h}$ :

Are you dry at night?

Yes

No

Date you became dry at night:

Are you dry all the time?

Yes

No

Date you became dry all the time:

1. Over the past 4 weeks, how often have you leaked urine?

Everyday. ... .

About once a week ...................

Less than once a week .................. 3

(Circle one number)
2. Which of the following best describes your urinary control DURING THE LAST 4 WEEKS: No problem ......................

Very small problem ..................

Small problem.......................2

Moderate problem .... 3 (Circle one number) Big problem. .

\section{. 4}

3. How big a problem, if any, has each of the following been for you? (Circle one number on each line)

a. Dripping urine or wetting your pants No problem, 0; Very small problem, 1; Small problem, 2; Moderate problem, 3; Big problem, 4 .

b. Urine leakage interfering with your sexual activity

No problem, 0; Very small problem, 1 ; Small problem, 2; Moderate problem, 3; Big problem, 4 .
Overall, how big a problem has your urinary function been for you during the last 4 weeks? (Circle one number)

No problem ..................... 0

Very small problem................. 1

Small problem...................... 2

Moderate problem .................. 3

Big problem.................. 4

No to all. ... 